\title{
SPECTROPHOTOMETRIC DETERMINATION OF PHOSPHATE IN SUGARCANE JUICE, FERTILIZER, DETERGENT AND WATER SAMPLES BY MOLYBDENUM BLUE METHOD
}

\author{
Samjhana Pradhan* and Megh Raj Pokhrel* \\ ${ }^{*}$ Central Department of Chemistry, Tribhuvan University, Kritipur, Kathmandu, Nepal.
}

\begin{abstract}
A simple and sensitive spectrophotometric method has been developed for the determination of phosphate in mg per liter (parts per million) concentration range in sugarcane juice, water, fertilizer and detergent samples. The amount of phosphate is determined by molybdenum blue phosphorus method in conjugation with UV-visible spectrophotometer. This method is based on the formation of phosphomolybdate complex with the added molybdate followed by the reduction of the complex with hydrazine hydrate in aqueous sulphuric acid medium. The system obeys Lambert-Beer's law at $840 \mathrm{~nm}$ in the concentration range $0.1-11 \mathrm{ppm}$. The colour intensity of the reduced phosphomolybdate solution is found to be proportional to the amount of phosphate present in sugarcane juice, water, fertilizer and detergent samples. The reaction conditions as well as the various experimental parameters affecting the development and stability of the coloured complex were carefully investigated and optimized for the quantitative determination of phosphate present in various samples. The optimized concentrations of various reagents used are $0.20 \mathrm{~N}$ sulphuric acid, $0.02 \mathrm{M}$ hydrazine hydrate and $0.20 \%$ ammonium molybdate. The effect of time on the formation of phosphomolybdenum blue complex and addition of the order of the reagents was also studied.
\end{abstract}

Keywords: Phosphate; UV-visible spectrophotometer; Molybdenum blue phosphorus method.

\section{INTRODUCTION}

Phosphorus is an important nutrient that occurs widely in the environment. It is the key elements necessary for the growth of plants and animals. It is the eleventh most abundant element on the surface of the earth and is most commonly found as phosphate ${ }^{1}$. Phosphorus is a pre requisite for microbial growth in the aqueous bodies. The increased concentration of phosphate is the key factor for the eutrophication of surface water. Heavy algal growth occurs when phosphate is present in water and as such is undesirable. Thus the determination of phosphorus is important to water analyst and limnologist ${ }^{2}$. Large quantities of phosphate have been used in detergents, fertilizers, sugar industries. A typical synthetic laundry detergent consists of a surfactant, builder and other miscellaneous ingredients including brighteners, perfumes, anti redeposition agents and sometimes enzymes also. Phosphates are excellent builders and are often used as either sodium tripolyphosphates (dry detergents) or sodium / potassium phosphates (liquid detergents). These phosphates are capable of tying up calcium, magnesium, iron and manganese ions, thereby improving overall washing performance. The builders are particularly necessary in hard water. Without builders, the manufacturers would have to add more surfactants which are relatively more expensive ${ }^{3}$. Phosphate is also important during sugarcane juice clarification leading to cane sugar manufacture. In this context, the chemical action of phosphate assumes a significant role particularly when the juice is deficient in natural phosphate content in range of $300-350 \mathrm{ppm}$ as $\mathrm{P}_{2} \mathrm{O}_{5}$ which is essential for good clarification. In case of less phosphate content in sugarcane juice, soluble phosphate addition is the only alternative to achieve the target value by adding ortho phosphoric acid, single super phosphate or triple super phosphate ${ }^{3}$.

The spectrophotometric molybdenum blue method for determining phosphate is a well established method. It involves the formation of molybdophosphoric acid from ortho phosphate and an excess of molybdate in acidic solution followed by reduction to give molybdenum blue. The absorbance of thus produced molybdenum blue is measured spectrophotometrically at a certain

Author for Correspondence: Megh Raj Pokhrel, Central Department of Chemistry, Tribhuvan University, Kritipur, Kathmandu, Nepal. E-mail: meghraj11@hotmail.com. 
wave length that gives maximum absorbance. The intensity of the blue color is proportional to the amount of phosphate present in the sample solution. Various reducing agents have been reported in the literature such as sodium sulphide, stannous chloride, and ascorbic acid and so on. But most of them suffer from some drawbacks such as stability of color, interferences from arsenic, the length of the time required for the full color development, sensitivity and absorption by the blank.

In this investigation, hydrazine hydrate has been used as the reducing agent for the reduction of molybdo phosphoric acid to molybdenum blue. The blank gives no color, which is the major advantage of this method.

\section{EXPERIMENTAL}

\section{Instruments}

The spectral measurements were made using ultraviolet visible spectrophotometer, model WPAS 104 UK with 1 $\mathrm{cm}$ matched quartz cells. An electronic balance, model GT $210 \mathrm{~V}$, OHAUS and a muffle furnace - WCR- muff - Nabertherm were used.

\section{Preparation of Standard Solutions}

All the chemicals used were of analytical reagent grade and the solutions were prepared in distilled water.

Phosphate stock solution: $0.717 \mathrm{~g}$ of potassium dihydrogenphosphate $\left(\mathrm{KH}_{2} \mathrm{PO}_{4}\right)$ was dissolved in distilled water and the volume was made $500 \mathrm{~mL}$ in a volumetric flask. The working phosphate solutions were prepared by its further dilution.

\section{Preparation of working solution of ammonium} molybdate $(2.5 \%)$

$50 \mathrm{~mL}$ of $5 \%$ ammonium molybdate reagent was diluted and made up to the mark in a $100 \mathrm{~mL}$ of volumetric flask.

\section{Preparation of sulphuric acid solution (10N)}

$28 \mathrm{~mL}$ of concentrated sulphuric acid solution was diluted and made up to mark in a $100 \mathrm{~mL}$ of volumetric flask.

\section{Preparation of hydrazine hydrate (0.5M)}

$2.44 \mathrm{ml}$ of concentrated hydrazine hydrate was diluted and made up to mark in a $100 \mathrm{~mL}$ of volumetric flask.

\section{Preparation of Samples}

\section{Water sample preparation}

The water samples collected from various places of Kathmandu were used for the phosphate analysis. The samples were filtered through Whatmann-41 filter paper in order to remove the insoluble particles. The filtrate contains orthophosphate, condensed phosphate (pyro, meta and poly forms) and organically bound phosphorus. All these forms of phosphate may be present in soluble form and in suspension. Since only ortho phosphate can be determined by molybdenum blue method so pyro, tripoly and polyphosphate were completely hydrolyzed to ortho phosphate by acidification $\left(2 \mathrm{~N} \mathrm{H}_{2} \mathrm{SO}_{4}\right)$ followed by heating for about 30 minutes and only after this it was used for the phosphate analysis.

\section{Sugarcane juice sample preparation}

Phosphate from sugarcane juice was analyzed without any further modifications. $5 \mathrm{~mL}$ of the sample juice was taken in a $100 \mathrm{~mL}$ volumetric flask and diluted up to the mark with distilled water and later used for the phosphate analysis.

\section{Detergent sample preparation}

$5.0 \mathrm{gm}$ of detergent sample was weighed in a crucible and placed in muffle furnace for about half an hour at $330^{\circ} \mathrm{C}$. Thus obtained ash was taken in a $250 \mathrm{~mL}$ beaker. It was then dissolved in $50 \mathrm{~mL}$ of distilled water. This solution was then acidified with sulphuric acid and heated on a hot plate for about 10 minutes to expel hydrogen sulphide, nitrite etc. It was then filtered through a Whatmann-41 filter paper and the filtrate was transferred into a $100 \mathrm{~mL}$ volumetric flask and diluted up to the mark with distilled water and was used for the phosphate analysis.

\section{Fertilizer sample preparation}

$5.0 \mathrm{gm}$ of fertilizer was weighed out and dissolved in $50 \mathrm{~mL}$ of distilled water. It was then filtered through a Whatmann-41 filter paper and the filtrate was taken in a $100 \mathrm{~mL}$ of volumetric flask and diluted up to the mark with distilled water. From this method only water soluble phosphate fertilizers were used for the phosphate determination.

\section{RESULT AND DISCUSSION}

The molybdenum blue method for the determination of inorganic phosphate is a well-established method. The blue color produced in this method is developed by the reduction of 12-molybdophosphoric heteropoly acid. Here the acidified solution of phosphate is treated with ammonium molybdate that gives hetero poly acid which is then reduced by hydrazine hydrate to give phosphomolybdenum blue i.e. a blue color complex. The reaction involved in the formation of molybdenum blue can be given as:

$\mathrm{PO}_{4}{ }^{3-}+12\left(\mathrm{NH}_{4}\right)_{2} \mathrm{MoO}_{4}+24 \mathrm{H}^{+} \rightarrow\left(\mathrm{NH}_{4}\right)_{3} \mathrm{PO}_{4} \cdot 12 \mathrm{MoO}_{3}$ $+21 \mathrm{NH}_{4}^{+}+12 \mathrm{H}_{2} \mathrm{O}$

$\left(\mathrm{NH}_{4}\right)_{3} \mathrm{PO}_{4} \cdot 12 \mathrm{MoO}_{3}+\left(\mathrm{N}_{2} \mathrm{H}_{4} \cdot \mathrm{H}_{2} \mathrm{O}\right) \rightarrow$ molybdenum blue

The absorbance of thus formed phosphomolybdenum blue was measured from $800 \mathrm{~nm}$ to $900 \mathrm{~nm}$ spectrophotometrically and $\lambda_{\max }$ was determined. The wavelength at which maximum absorbance was observed was considered as the $\lambda_{\max }$. On plotting absorbance against wavelength, the wavelength of maximum absorption $\left(\lambda_{\max }\right)$ was found at $840 \mathrm{~nm}$ for the given phosphate solution which is shown in the Figure $1^{4}$. 


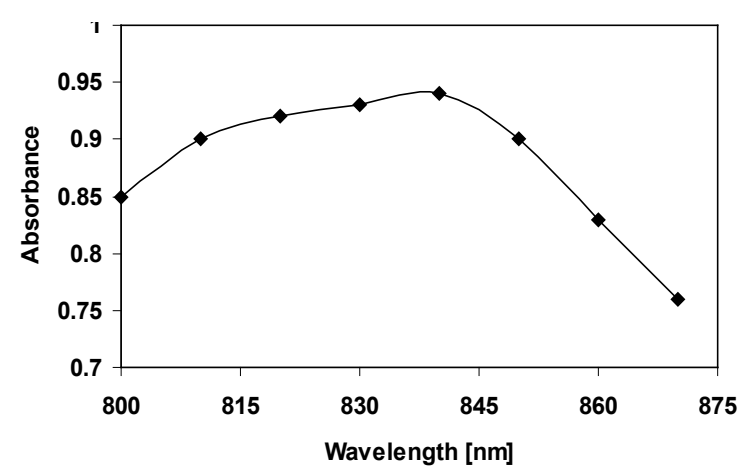

Fig 1: Plot of absorbance against wavelength [for phosphomolybdenum blue complex] for determination of $\lambda_{\max }$

The reaction conditions as well as the various experimental parameters such as concentration of ammonium molybdate, sulphuric acid, hydrazine hydrate, order of the addition of the reagents and also color stability of the complex were optimized for the effective determination of phosphate.

Optimization of concentration of various reagents for the determination of phosphate

\section{a. Optimization of concentration of sulphuric acid}

The intensity of the color of phospho molybdenum blue complex is significantly affected by the acidity of the solution. In order to achieve maximum absorbance, the effect of concentration of sulphuric acid was investigated by taking various volumes (0.1-1.0 $\mathrm{mL}$ ) of $10 \mathrm{~N}$ of sulphuric acid, $2 \mathrm{~mL}$ of ammonium molybdate $(2.5 \%), 2 \mathrm{~mL}$ of phosphate solution (50 ppm) and $1 \mathrm{~mL}$ of hydrazine hydrate $(0.5 \mathrm{M})$ in a 25 $\mathrm{mL}$ volumetric flask. Then the solutions were diluted and made up to the mark with distilled water and left for 35 minutes for maximum color development. After this the absorbance of each solution was measured at 840 $\mathrm{nm}$. The absorbance values indicated that the solution of $0.20 \mathrm{~N}$ sulphuric acid appeared to be more sensitive and hence was used throughout the experiment for the determination of phosphate. The plot of absorbance as a function concentration of sulphuric acid is shown in Figure 2. The blue color of the solution is obtained only in acidic medium. At high acidity the color intensity decreases. This is mainly due to the reason that at high acidity the formation of phospho molybdenum blue complex decreases ${ }^{5}$.

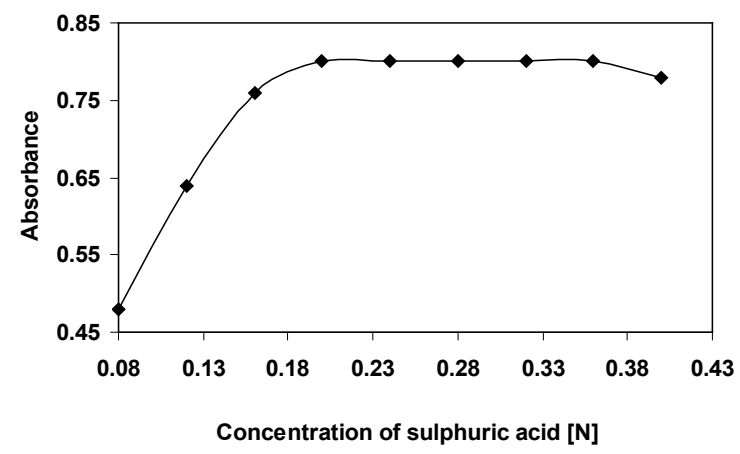

Fig 2: Optimization of concentration of sulphuric acid

\section{b. Optimization of concentration of ammonium molybdate}

The concentration of ammonium molybdate also plays a significant role in the formation of phospho molybdenum blue complex. The effect of concentration of ammonium molybdate on the on the formation of phospho molybdenum blue complex was investigated by varying the volumes $(0.1-8) \mathrm{mL}$ of ammonium molybdate $(2.5 \%)$, with the addition of $0.5 \mathrm{~mL} 10 \mathrm{~N}$ sulphuric acid, $2 \mathrm{~mL}$ of phosphate solution (50 ppm) and $1 \mathrm{~mL}$ of hydrazine hydrate $(0.5 \mathrm{M})$ in a $25 \mathrm{~mL}$ volumetric flask and then made up to mark with distilled water. After the time for maximum color development the absorbance of these solutions were measured at $840 \mathrm{~nm}$. The absorbance values indicated that the solution of $0.20 \%$ ammonium molybdate appeared to be more sensitive and hence was used throughout the experiment for the determination of phosphate. The plot of absorbance against concentration of ammonium molybdate is shown in Figure 3.

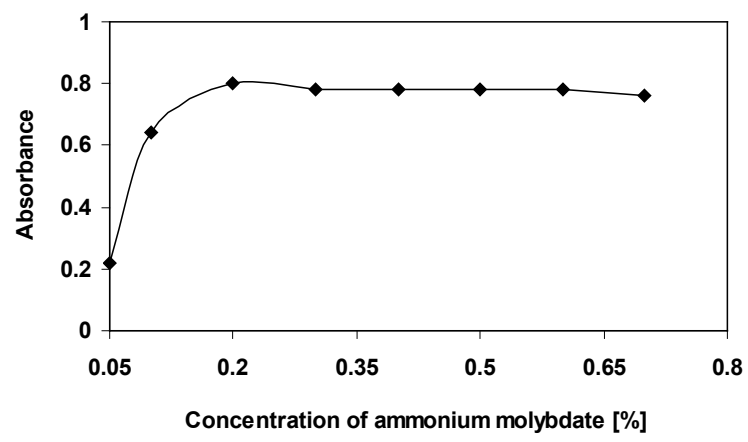

Fig 3: Optimization of concentration of ammonium molybdate

\section{c. Optimization of concentration of hydrazine hydrate}

In molybdenum blue method the reducing agent reduces the phospho molybdic acid thereby giving phospho molybdenum blue. Hence the formation of phospho molybdenum is also dependent on the concentration of reducing agent i.e. hydrazine hydrate. The concentration of hydrazine was optimized by varying the volumes of $0.5 \mathrm{M}$ hydrazine hydrate $(0.1-4 \mathrm{~mL})$ in a $25 \mathrm{~mL}$ volumetric flask. A plot of absorbance as a function of concentration of hydrazine hydrate is shown in Figure 4. The absorbance shows that with increase in concentration of hydrazine hydrate, the absorbance value also increases. After the addition of $1 \mathrm{~mL}$ of hydrazine hydrate the absorbance value remains constant throughout. So based on this result $1 \mathrm{~mL}$ of 0.5 M hydrazine hydrate solution was used throughout the experiment. 


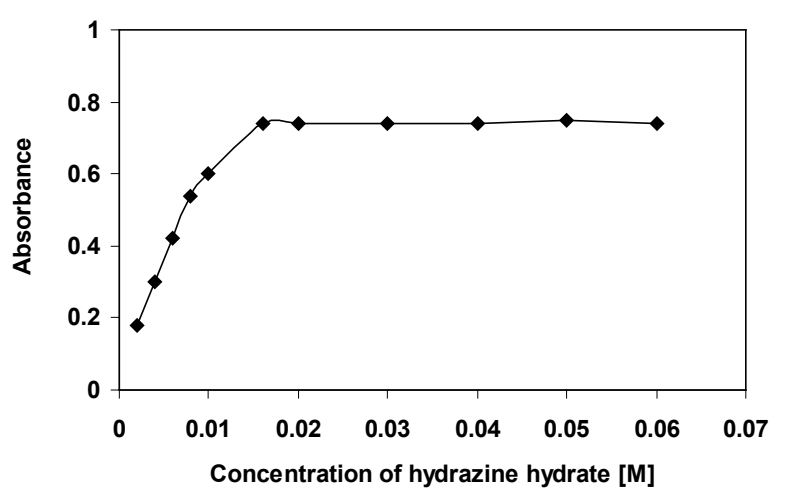

Fig 4: Optimization of concentration of hydrazine hydrate

\section{d. Effect of time on the formation of phospho molybdenum complex}

The formation of phospho molybdenum complex is time dependent. Initially the rate of blue color formation is very slow which gradually increases with time and remains constant for certain period of time. Further increase with time (after 60 minutes) results in the decrease in absorbance. A plot of absorbance as a function of time is shown in Figure 5. The absorbance value shows that the maximum value of absorbance is observed at 35 minutes which remains constant for about 25 minutes and after 1 hour the absorbance starts decreasing. This may be due to the dissociation of phospho molybdenum blue complex ${ }^{6}$. Hence the formation of phosphomolybdenum blue is time dependent.

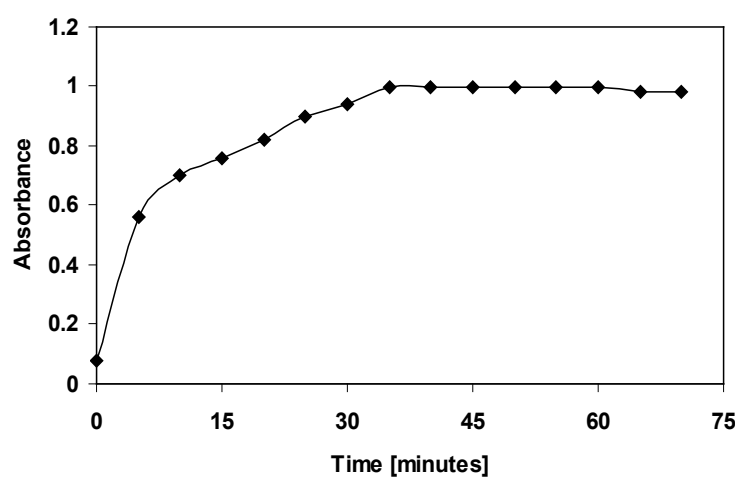

Fig 5: Effect of time on the formation of phosphomolybdenum blue complex

\section{e. Effect of order of the addition of reagents}

By using the optimized amounts of the reagents, different orders of the reagent addition was also studied. The results thus obtained have shown that the order of the addition of the reagents do not effect absorbance values. But in order to maintain the uniformity of order of the reagent addition the following procedure was followed throughout the experiment:

1-2 mL of sample

$$
\downarrow
$$

$2 \mathrm{~mL}$ of $2.5 \%$ ammonium molybdate<smiles>[AlH]</smiles>

$0.5 \mathrm{~mL}$ of $10 \mathrm{~N}$ sulphuric acid
$1 \mathrm{~mL}$ of $0.5 \mathrm{M}$ hydrazine hydrate

$\downarrow$

Dilute up to the mark in $25 \mathrm{~mL}$ volumetric flask

$$
\downarrow
$$

Measure the absorbance

\section{f. Calibration curve}

Calibration curve is necessary to establish a relation between the absorbance and the phosphate content for spectrophotometric analysis. The calibration curve for the phosphate analysis is shown in Figure 6. The curve is obtained by plotting absorbance as a function of concentration of phosphate (in ppm) at the wavelength $840 \mathrm{~nm}$. The plot is linear and obeys Lambert-Beer's law in the range 0 to $11 \mathrm{ppm}$. The amount of phosphate within this range can be determined. Above this range the sample should be diluted in order to bring the concentration with in the measurable range.

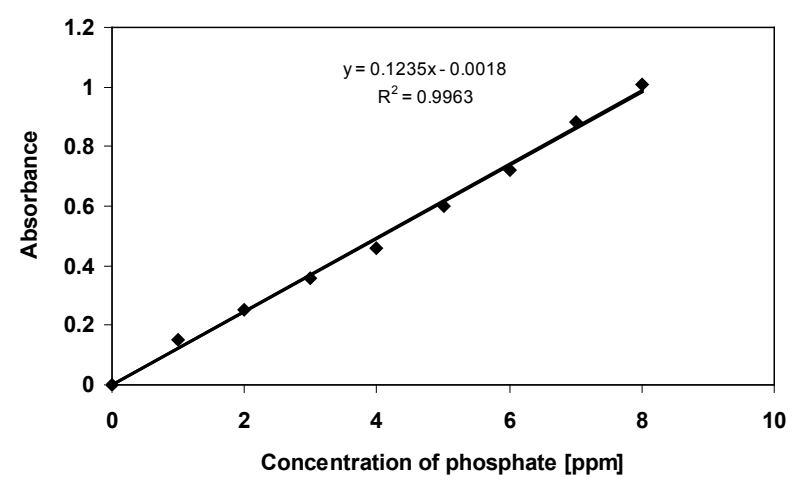

Fig 6: Calibration curve for the determination of phosphate

\section{g. Determination of phosphate in various samples}

The concentration of phosphate in various samples viz. sugarcane juice, detergent, fertilizer and water samples was determined spectrophotometrically by molybdenum blue method which can be shown Tables below. In each case, $2 \mathrm{~mL}$ of sample solution was taken followed by the addition of the reagents under optimized conditions. Each sample was then left at room temperature for about 35 minutes for maximum color development and hence the absorbance was measured spectrophotometrically. The results of these analyses are shown in Tables 1 to 4 .

Table 1. Determination of phosphate in water .

\begin{tabular}{cc}
\hline Samples & Phosphate in $\mathbf{~ m g / L}$ \\
\hline W-1 & 7.46 \\
W-2 & 3.57 \\
W-3 & 3.01 \\
W-4 & 1.31 \\
W-5 & 2.28 \\
W-6 & 5.52 \\
W-7 & 1.79 \\
W-8 & 0.5 \\
W-9 & 0.6 \\
\hline
\end{tabular}


Table 2: Determination of phosphate in sugarcane juice.

\begin{tabular}{lc}
\hline Samples & Phosphate in $\mathbf{~ g / L ~}$ \\
\hline S-1 & 180 \\
S-2 & 160 \\
\hline
\end{tabular}

Table 3: Determination of phosphate in detergent .

\begin{tabular}{lc}
\hline Samples & Phosphate in $\mathbf{~ g / L ~}$ \\
\hline D-1 & 63.2 \\
D-2 & 20.3 \\
D-3 & 21.1 \\
D-4 & 34.5 \\
D-5 & 59.2 \\
D-6 & 21.9 \\
D-7 & 19.9 \\
D-8 & 75.3 \\
\hline
\end{tabular}

Table 4: Determination of phosphate in fertilizer.

\begin{tabular}{lc}
\hline Samples & Phosphate in $\mathbf{~ m} / \mathbf{L}$ \\
\hline F-1 & 47 \\
F-2 & 70.5 \\
\hline
\end{tabular}

\section{h. Recommended procedure for the determination of} phosphate in various samples

The following procedure has been recommended for the determination of phosphate:

i) In a 25 volumetric flask, take $1 \mathrm{~mL}$ of sample then add $2 \mathrm{~mL}$ of $2.5 \%$ ammonium molybdate and 0.5 $\mathrm{mL}$ of $10 \mathrm{~N}$ sulphuric acid solutions. Shake well the reaction mixture.

ii) Add $1 \mathrm{~mL}$ of $0.5 \mathrm{M}$ hydrazine hydrate solution

iii) Make the volume up to mark by adding distilled water.

iv) Leave the solution for maximum color development at least for about 45 minutes.

v) Then measure the absorbance at $840 \mathrm{~nm}$.

vi) Calculate the amount of phosphate in ppm (mg/L) from calibration curve.

vii) If the absorbance becomes out of range then dilute the sample solution and follow the above procedure.

\section{CONCLUSION}

The phosphate determination by molybdenum blue method in conjugation with uv-visible spectrophotometer is a simple method that can be carried out in common laboratories. The method is simple and cheap compare to other methods, because it neither involves extraction of the analyte, nor requires any sophisticated instruments like HPLC. The strict control of $\mathrm{pH}$ is not necessay in this method. In addition, the developed new method is working satisfactorily for the determination of phosphate present in various samples analyzed. The system obeys Lambert-Beer's law in the phosphate concentration range 0.1-11 ppm. The work presented here reports the optimization of reaction conditions and the concentration of the various reagents for spectrophotometric determination of phosphate in various samples by molybdenum blue method. The optimized concentrations of various reagents were found to be as follows: $2 \mathrm{~mL}$ of $2.5 \%$ ammonium molybdate, $0.5 \mathrm{~mL}$ of $10 \mathrm{~N}$ sulphuric acid solution, $1 \mathrm{~mL}$ of hydrazine hydrate $(0.5 \mathrm{M})$ in the final volume of $25 \mathrm{~mL}$. This method depends on the freshness of the reagents used, temperature and stability of the molybdenum blue complex. The maximum time taken for the formation of phospho molybdenum blue complex was found to be 45 minutes at a temperature of $30^{\circ} \mathrm{C}$. At low temperature, the rate of formation of complex was slow and hence low absorbance value was observed. At high temperature (above $50^{\circ} \mathrm{C}$ ) also the absorbance value was low which may be due to the dissociation of the phosphomolybdenum blue complex. The optimized method has been successfully applied for the determination of amount of phosphate in various samples viz. detergent, fertilizer, sugarcane juice and water.

\section{ACKNOWLEDGEMENT}

The authors are highly grateful to the Head of the Department, Central Department of Chemistry, Tribhuvan University, Kathmandu, Nepal for providing the available research facilities to conduct this research work.

\section{REFERENCES}

1. Chaube, M.A., Gupta, V.K. 1983. Spectrophotometric Determination of Phosphate in Polluted Waters by Solvent Extraction of Molybdenum Blue, Analyst. 108: 1141-1144.

2. Kharat, S.J., Pagar, S.D. 2009. Determination of Phosphate in Water Samples of Nashik District Rivers by UV-Visible Spectroscopy. E-Journal of Chemistry. 6 (S1): S515-S521.

3. Bartels, P.C., Roijers, A.F.M. 1975. A Kinetic Study on the Influence of the Parameters in the Determination of Inorganic Phosphate by the Molybdenum Blue Reaction, Clinica Chimica Acta. 61: 135-144.

4. Machacek, Y., Malat, M. 1981. A New Extraction Method for the Spectrophotometric Determination of Phosphates. Microchemical Journal. 26: 307-315.

5. Ohashi, K., Kawaguchi, H., Yamamota, K. 1979. Simultaneous Kinetic Determination of Phosphate Silicate based on Heteropoly Blue Formation, Analytica Chimica Acta. 111: 301-306.

6. Huang, X.L., Zhang, J. Z. 2008. Kinetic Spectrophotometric Determination of Submicromolar Orthophosphate by Molybdate Reduction, Microchemical Journal. 89: 58-71.

7. Galhardo, C.X., Masini, J.C. 2000. Spectrophotometric Determination of Phosphate and Silicate by Sequential Injection using Molybdenum Blue Chemistry. Analytica Chimica Acta. 417: 191-200.

8. Jalali, M. 2007. Phosphorus Status and Sorption Characteristics of some Calcareous Soils of Hamadan, Western Iran. Environmental Geology. 53: 365-374. 